\title{
Palmar and plantar psoriasis and homeopathy - Case reports
}

\section{Lawrence Chukwudi Nwabudike}

\author{
N. Paulescu Institute of Diabetes, Str. I.L. Caragiale, Nr. 12, Sector 2, Bucharest, Romania
}

Corresponding author: Dr. Lawrence Chukwudi Nwabudike, E-mail: Chukwudi.nwabudike@live.com

\begin{abstract}
Psoriasis is a chronic cutaneous disorder, which is protean in its manifestation. It is a significant source of morbidity and mortality. It is associated with arthropathy as well as disorders such as diabetes mellitus and coronary artery disease. Therapeutic guidelines offer a wide range of topical and systemic treatments, yet a number of patients are often dissatisfied with the treatment of their disease and, in consequence, seek other alternatives. Homeopathy is a gentle, safe method of treatment that would appear to have positive effects in the treatment of psoriasis. Three cases of palmar and plantar psoriasis treated with homeopathy are presented.
\end{abstract}

Key words: Palmar and plantar psoriasis; Homeopathy; Homeopathic medicine; Drug-aggravated psoriasis

\section{INTRODUCTION}

Psoriasis is a chronic inflammatory disorder with cutaneous and extracutaneous manifestations. Its prevalence varies from $0 \%$ in Taiwanese children to $8.5 \%$ in Norwegian adults [1]. There are various forms of psoriasis, which may be localized or generalized, including the plaque, guttate, pustular, flexural, erythrodermic, nail, articular, oral and ocular forms.

Management includes topical and systemic therapy, followed by maintenance therapy to maintain remission.

Homeopathy is a form of treatment that has evidence of efficacy in the management of psoriasis and may not require maintenance treatment, following remission [2,3]. Homeopathic medicines are known to rarely produce side-effects and are also cheap.

Presented in this paper are three cases of palmar and plantar psoriasis treated with homeopathy.

\section{CASE REPORTS}

\section{Case 1}

A 55-year old female, with a 4-month history of rash on her left sole with nail lesions affecting her left large toe. Past medical history was significant for Type 2 diabetes mellitus and hypertension. Examination revealed a single, hyperkeratotic plaque on the sole of the left foot, with occasional vesicles. She also had a hyperkeratotic area of skin on her left big toe, with nail dystrophy. Fungal examination was negative. She had received a topical steroid cream, followed by a herbal preparation, both of which failed to help. She was prescribed the homeopathic medicine Staphysagria, at MK potency, weekly. She went into remission in 6 months, but relapsed. Review showed that she had been on angiotensin converting enzyme (ACE) inhibitors. The cardiologist subsequently changed her medication to verapamil and she went into remission once more, with growth of nails and clearance of the toe and plantar lesions (Fig. la-c). 


\section{Case 2}

A 65-year old female presented with a 4-year history of a palmar rash, previously treated as eczema and fungal infection unsuccessfully. Examination revealed erythematous plaques on palms of hands. Biopsy confirmed psoriasis. The patient received the homeopathic medicine Lycopodium, MK potency, weekly, with remission within 3 months and remains in remission 2 years later. This patient also had received Beta-blockers during the period of remission, which caused flare-ups, with axillary lesions. The flares remitted upon substituting with rilmenidine(Fig. 2a-c).

\section{Case 3}

A 64-year old male presented with a history of generalized rash of 30 years duration. The rash was associated with intense itch. The rash was also present in the palmar and plantar areas, manifesting as hyperkeratosis and fissuring with erythema and mild swelling. This was a source of distress for him both personally and professionally as the patient is a driver by profession.

A biopsy was carried out, which confirmed the suspicion of psoriasis. He was given the homeopathic medicine Tuberculinum at MK potency, to be taken weekly, the homeopathic medicine Sulphur at CH30 potency to be taken for the itch and bland soaps and emollients were recommended.

The patient improved gradually with marked improvement of the palmar and plantar areas at 4 months of treatment and improvement of other skin areas, together with reduction in itch. The palmar and plantar lesions were in full remission at 1 year, together with most body areas (Fig. 3a-d).

\section{DISCUSSION}

Psoriasis is a chronic inflammatory disease. It is characterized by periods of spontaneous regression of variable length. Topical and systemic therapies are recommended, according to international clinical guidelines [4,5]. Maintenance therapy is often the rule, in order to avoid relapse. Complications, which may sometimes be severe, especially with the biologic agents, may occur. The cost of treatment can be very high and prohibitive especially for those not on health insurance.
Comorbidities may be associated with psoriasis and their treatment may affect the course of the disease. This was the case with patients 1 and 2, who relapsed

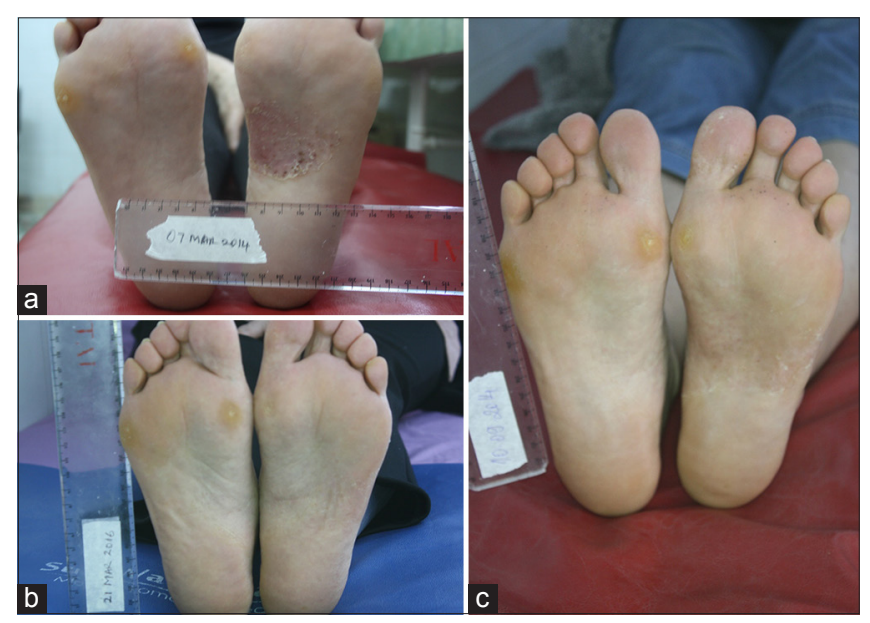

Figure 1: a) Erythematosquamous, well-defined plaque, on left sole of foot. The right sole has calluses. b) Patient still in full remission 18 months later and after removal of ACE inhibitor therapy, c) Patient in full remission.

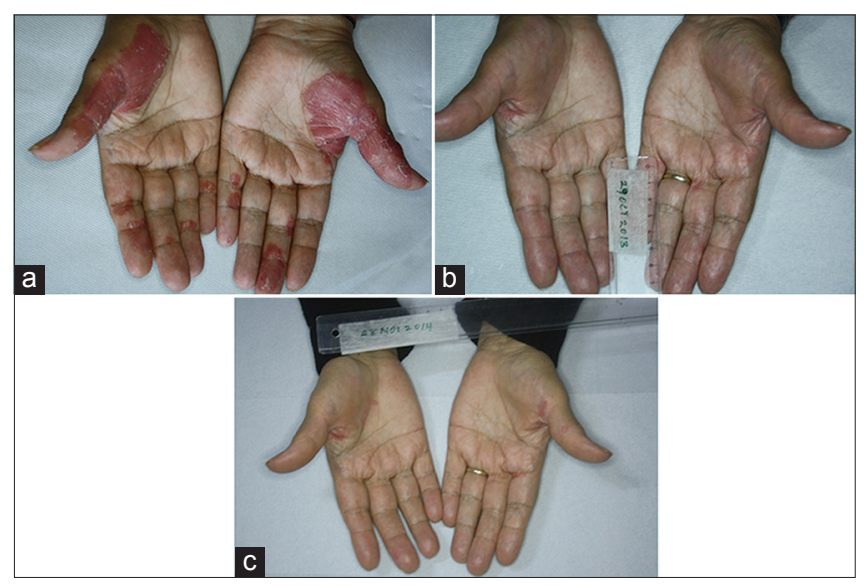

Figure 2: a) Erythematous, well-defined plaques on the palms and plantar aspects of fingers bilaterally. b) Patient in remission after 3 months. c) Patient still in remission.

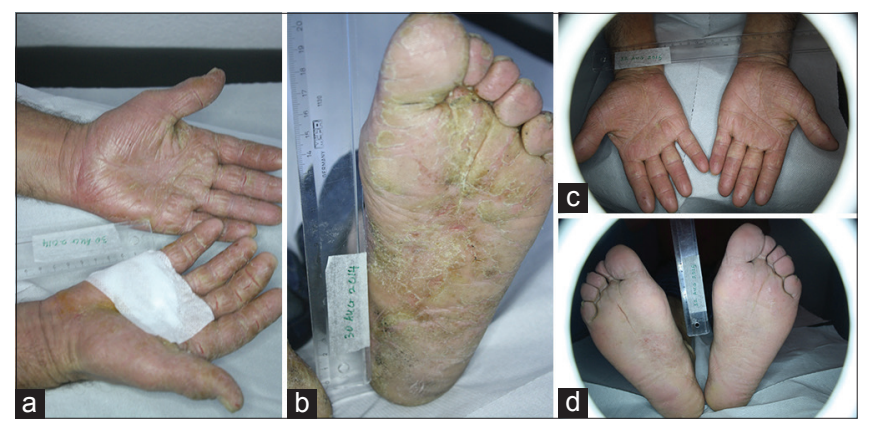

Figure 3: a) Erythema, hyperkeratosis and deep fisiuring of both palms. The dressing is for the biopsy area. b) Hyperkeratosis of soles of foot. c) Patient in remission. Palmar hyperkeratosis, erythema and fissuring gone. d) Patient in remission. Plantar hyperkeratosis gone. 
following treatment with ACE inhibitors and betablockers respectively, for hypertension. The patients subsequently improved upon withdrawal of the suspect medication. ACE inhibitors and beta-blockers are two classes of drugs, which have been associated with onset or exacerbation of psoriasis, amongst other medications such as NSAIDS, antimalarials, lithium, benzodiazepines, tetracyclines and dipyrone [6,7]. Such a reaction, occurring in patients with a history of psoriasis, has been designated as "drug-aggravated psoriasis" and tends to continue even after the removal of the offending agent [7]. Improvement resumed after the removal of the offending drug, which may be an indication of efficacy of homeopathy as opposed to a spontaneous remission and may indicate the possible usefulness of homeopathy for this form of psoriasis also.

Homeopathy is a safe, cheap method of treatment that has also been found to be useful in certain cutaneous disorders, including atopic dermatitis [8], eczema [9], lichen striatus [10], seborrheic dermatitis [11], melasma [12], rosacea [13], dermatitis herpetiformis [14], verucca vulgaris [15], as well as psoriasis $[2,3]$.

The mechanism of action of homeopathy in general and in skin diseases in particular is still not elucidated. What appears to be known is that highly diluted solutions emanate electromagnetic signals that mimic that of the original solute and that the water molecules in which the solute was originally dissolved form nanoparticles that appear to be identical to the original solute molecule [16,17]. These nanoparticles may then act to ameliorate the disease.

Although Witt et al [2] showed clear improvement in clinical lesions of psoriasis as well as quality of life scores, other authors in an earlier work suggest that there is no beneficial effect [18] of homeopathy in the therapy of psoriasis. This difference may be due to different population characteristics, as the positive study [2] was carried out amongst patients that were treated by classical homeopathy (the form used in this study also), which is individualized and tailored to each patient. Classical homeopathy is often the preferred method for deep-seated, chronic ailments. The patients in the negative study were drawn from those visiting an outpatient clinic and the method of homeopathic treatment not specified [18].

A recent study has shown a $15 \%$ increase in the number of adults using homeopathy in the United States [19].
This study also highlighted the fact that the patients mostly perceived a positive effect from their treatment.

\section{CONCLUSION}

Psoriasis can take many forms and the palmoplantar form is one of them. This form of psoriasis presents many challenges as the ability to work would be affected by both the cosmetic aspect of the disorder and the discomfort it would cause. Case three was a very clear example of this. Palmoplantar psoriasis may be mild and hard to detect or involve the entire palmar and plantar surface. The differential diagnosis includes eczema, dermatophyte infection, palmoplantar pustulosis, Reiter's disease and pompholyx.

Usually, the diagnosis of palmoplantar psoriasis is straightforward, but some cases required biopsy for confirmation.

Clinical improvement was sustained in these cases, following homeopathic treatment. Some cases relapsed following introduction of ACE inhibitors and beta-blockers, subsequently improving upon their removal, which may also be evidence of the efficacy of the homeopathic treatment, counting against a coincidental improvement, as drug-aggravated psoriasis does not improve after the removal of the offending agent, where no effective treatment is in place [7].

Homeopathy is a cheap and gentle form of treatment, which rarely produces side-effects. In an era of limited health budgets, where patients seek alternative solutions for their chronic disorders, there may be a place for homeopathy in the care of their chronic skin disorders.

Larger studies would probably be required to elucidate the place homeopathy might occupy in the treatment of patients with palmoplantar psoriasis.

\section{REFERENCES}

1. Parisi R, Symmons DP, Griffiths CE, Ashcroft DM. IMPACT Team. Global epidemiology of psoriasis: a systematic review of incidence and prevalence. J Invest Dermatol. 2013;133:377-85.

2. Witt CM, Lüdtke R, Willich SN. Homeopathic treatment of patients with psoriasis - a prospective observational study with 2 years follow-up JEADV. 2009;23:538-43.

3. Nwabudike LC. Psoriasis and homeopathy. Proc Rom Acad Series B. 2011;3:237-42.

4. Menter A et al. Guidelines for care for the management of psoriasis and psoriatic arthritis. JAAD. 2011;65:137-74.

5. Pathirana D, Ormerod AD, Saiag P, Smith C, Spuls PI, Nast A, 


\section{www.odermatol.com}

et al. European S3-guidelines on the treatment of psoriasis vulgaris. JEADV. 2009;23:5-70.

6. Cohen AD, Bonneh DY, Reuveni H, Vardy DA, Naggan L, Hallevy S. Drug exposure and psoriasis: Case control and casecrossover studies Acta Derm Venereol. 2005;85:299-303.

7. Kim GK, Del Rosso JQ Drug-provoked psoriasis: is it drug induced or drug aggravated? J Clin Aesth Dermatol 2010;3:32-8.

8. Nwabudike LC. Atopic dermatitis and homeopathy. Our Dermatol Online. 2012;3:217-20.

9. Signore RJ. Classic homeopathic medicine and the treatment of eczema. Cosm Derm. 2011;24:420-5.

10. Signore RJ. Treatment of lichen striatus with homeopathic calcium carbonate. Jl Amer Ost College Derm. 2011;21:43.

11. Nwabudike LC. Seborrheic dermatitis and homeopathy. Our Dermatol Online. 2011;2:208-10.

12. Nwabudike LC. Melasma and Homeopathy. Homeopathic Links. 2012;25:99-101.

13. Nwabudike LC. Rosacea and Homeopathy. Proc Rom Acad Series B. 2012;14:207-11.

14. Nwabudike LC. Homeopathy in the treatment of dermatitis herpetiformis - a case presentation Homeopathic Links. 2015;28:44-6.
15. Nwabudike LC. Homeopathy in the treatment of verruca vulgaris An experience of two cases. Proc Rom Acad Series B. 2010;2:147-9.

16. Montagner L, Aïssa J, Ferris S, Montagner J-L, Lavallée C. Electromagnetic signals are produced by aqueous nanostructures derived from bacterial DNA sequences. Interdiscip Sci Comput Life Sci. 2009;1:81-90.

17. Chickramane PS, Suresh AK, Bellare RJ, Kane GS. Extreme homeopathic dilutions retain starting materials: A nanoparticulate perspective. Homeopathy. 2010;99:231-42.

18. Jenssen P. Alternative therapy for atopic dermatitis and psoriasis: patient-reported motivation, information source and effect. Acta Derm Venerol. 1990;70:425-8.

19. Dosset ML, Davis RB, Kaptchuk TJ, Yeh GY. Homeopathy use by US adults: Results of a national survey. Am J Public Health. 2016;106:743-5.

Copyright by Lawrence Chukwudi Nwabudike. This is an open access article distributed under the terms of the Creative Commons Attribution License, which permits unrestricted use, distribution, and reproduction in any medium, provided the original author and source are credited.

Source of Support: Nil, Conflict of Interest: None declared. 